\title{
Empowering students as researchers: Teaching and learning autoethnography and the value
}

\section{of self-narratives}

\begin{abstract}
Helping students to connect their academic research with their creative writing processes is often a challenge but when achieved, can provide valuable pathways between their personal experiences and the social world under study. The author identifies supporting this connection as a potentially powerful teaching and learning tool, helping undergraduates to make the leap from student to writer and researcher. This chapter will identify possible ways in which the writing and sharing of autobiographical narratives can inform and enhance pedagogy in creative writing workshops with undergraduate students. The author identifies autoethnography as an evolving methodology that values and legitimizes personal stories and evocative academic work, and can facilitate recovery from personal events that have been difficult or traumatic (Richardson and St Pierre 2005). The chapter will explore how the study of self-narrative can empower students to make explicit links between these personal experiences and their academic research. This chapter will be of interest to teachers and students carrying out research in education and to those trying to develop their own teaching practice to incorporate student-focussed approaches to creative writing. The author suggests that an autoethnographic approach can contribute to an increased confidence in students' sense of their place within the discipline of creative writing and the place of their discipline within the wider world.
\end{abstract}

Keywords: autoethnography, creative writing, narrative, higher education, teaching

\section{Introduction}

"Good autoethnography is ... a provocative weave of story and theory" (Denzin 1992, p.25)

Creative writing workshops can and must provide safe ground for developing the imagination and the sharing of stories. In my own teaching, I have always tried to encourage students to view the discipline of Creative Writing as a craft, an arts-based practice that can (and should) be informed by research. They should be encouraged to play and take risks and not damage themselves with 
vicious self (or even peer or tutor) critique but they should also recognise that it is a discipline, as important as any other, and that research can (and will) inform and enrich their study and process. The process of making is central to developing knowledge (Knights, 2008; Charney, 2011) and this needs to be acknowledged and celebrated in our teaching of creative writing. Equipping students with the skills to hone and craft their ideas into evocative texts in a variety of genres is an essential part of any writing course, but it is also important that students have the confidence to draw on their lived experiences and consider ways to bring their autobiographical narratives (back) to life.

When I started as a creative writing tutor on undergraduate and postgraduate modules at the University of Brighton in 2006, I discovered a tension between asking students to engage in a process of developing self-narratives whilst simultaneously suggesting that they remove the 'I' when they discuss their writing practice in their academic essays. It was a tension I experienced in my own work when completing a doctorate - why must we deny a personal link to our writing? Why must we pretend to be objective when how we view and experience the world and the narratives we develop are often inextricably linked? My research into autoethnography helped me to identify a methodology that allows me to talk about my own experiences and for this be a valued component of my academic work. I now regularly adopt an autoethnographic approach to my research and writing and have used it to argue that creative and evocative writing, including autobiographical narratives, should be viewed as a rich research tool and a way of accessing insider accounts as to what things can be and are like. My own work has explored experiences with academic writing via a script that drew on my experiences and interview data from academics at varying stages of their career (Moriarty, 2015a); adopted a splintered narrative that merged script, poetry and memoir to detail my experiences of completing a creative $\mathrm{PhD}$ (Moriarty, 2015b); and a study of the effects of neo-liberalism using autoethnodrama (Moriarty, 2016). Having been told that any creative writing I produced would not be deemed worthy for the Research Excellence Framework (REF), the framework used for judging academic's success in terms of academic writing (Canagarajah, 2002), it has been an absolute revelation to discover a methodology that permits creative work in academic research. In this way, I can allow research to inform my practice and present my findings via academic books, journal articles and chapters and also at conferences and in my teaching too. Instead of feeling fraudulent when I talk about writing in workshops and seminars, I now feel I can balance the expectations of my institution for publishable academic work with my own desire to write creatively and share what that experience and process is like with my students. It has brought me some balance in my academic life and at a 
time of increasing pressure to do more for less and a shift towards a more neo-liberal audit culture in HE (Doherty, 2014), this balance is not merely desirable, it is vital. In this chapter I explore the potential benefits of working with students on autoethnographic work and how it can inform and enhance their life writing, their confidence with their studies and also with themselves.

The benefits of linking my autobiographical experiences with the material I was studying via evocative and creative writing and research was transformational. But what I was advocating was so contrary to the style of traditional journal articles, chapters and handbooks that even as a doctoral student, I had been advised that my work might not be viewed as rigorous or 'academic' enough. Even now in 2016, I still receive rejection letters from journals dismissing creative writing in scholarly work. Undergraduate and postgraduate students are often resistant to explicitly research-led practice, preferring just to do creative work (Cardell and Douglas, 2016). This coupled with the introduction of fees which has changed and intensified the pressure to do well at university means that persuading already reticent students to gamble their increasingly expensive degree by employing a methodological stance that is 'other' to dominant conventional academic practice can be a challenge. Legitimising creative writing as an academic discipline by enhancing its epistemological status and engaging students with ways of conducting research that are potentially more democratic and inclusive make this challenge not only welcome but necessary. How then, to bring emerging research methodologies that link research and writing practice to my teaching of self-narratives and encourage students to engage with research methods that resist the established, conventional practices of academic writing that dominate academic discourse at almost every level?

\section{Autoethnography}

The study of the researcher as subject of investigation is evident in many social science disciplines including anthropology (Reed-Danahay, 1997), sociology (Denzin, 1997, 2006; (Lucal, 1999)), communications (Ellis, 1995, 2004; Ellis and Bochner, 2000), education (Clough, 2002) sport and physical education (Sparkes, 2002) mental health (Grant, 2010; Grant and Zeeman, 2010). Autoethnography is a methodology that legitimises academic research where the writer details their personal experiences, often through stories and autobiographical narratives, that situate them in the social world or culture under study (Reed-Danahay, 1997). To this end, autoethnography is a process of research but it is also concerned with the product of that process. Reed-Danahay (1997) defines autoethnography as "research (graphy) that connects the personal 
(auto) to the cultural (ethnos), placing the self within a social context” (Reed-Danahay, 1997, p.145). Autoethnographers story their lived experiences via emotionally rich texts that seek to actively resist and challenge dominant academic discourse. Autoethnographies explore messy and complicated real lives that are never just one thing or just another, which goes against the traditional, objective and omnipotent style of traditional research texts. Autoethnographers ask the reader to think with stories rather than about them (Frank, 2001) which is why it is synonymous with creative work and artist practice. The artist doesn't tell you what to think about their work, they have ideas, carry our research and have an informed process, they produce and then they wait to see what the effects are. And this can be likened to processes in autoethnographic work.

In autoethnography, the writing up of data can be descriptive-realistic, confessional-emotive, analytical-interpretive, creative-imaginative, etc., and draws on short stories, memoir, scripts, poetry and other forms of creative and personal writing that help the researcher to locate themselves in the society or culture they are investigating and connect with the reader on an emotional and personal level whilst also contributing to intellectual debate. These stories are predominantly written in the first person and use emotional and self-aware accounts that demonstrate how the writer has been affected by the social group and/or culture under investigation (Ellis and Bochner, 2000). Autoethnographers challenge conventional and objective presentations of research data where the researcher's voice is usually absent and encourage empathetic readings that contribute to an enhanced social understanding (Sparkes, 2002). Writing in this way provides a useful tool in teaching creative writing that seeks to engage students with the process of telling their autobiographical stories in a range of styles and genres which is linked to a rigorous research process of data collection and analysis.

With autoethnographic work, autobiographical and biographical stories about a particular social group or culture or experience can help the reader understand or better understand what or who it is under study, but also help the researcher to better understand themselves. Laurel Richardson describes this as writing as a method of inquiry (Richardson, 2000). In this context, stories can be told in the spirit of social justice by interrogating and critiquing potentially (or actually) repressive cultural institutions, norms, values, practices and logics (Grant, 2010b). By engaging with a text on an emotional and theoretical level, it is hoped that the reader will make better sense of their own lives by considering themselves in relation to what they have read (Frank, 2011). This process enables students storying their autobiographical experiences to take an objective stance and this detachment is often necessary when critiquing and editing their raw autobiographical 
material. Creative writing students, as with all writers, can struggle to distance themselves from their autobiographical writing and this can result in them producing work that whilst emotional and moving, lacks the technique and crafting of 'good' writing. Writing for therapy is an important and useful strategy for coping with difficult or traumatic experiences but creative writing courses in HE are also concerned with producing skilled writers who can create texts they feel confident to share with their peers, tutors and submit for assessments, competitions, performance etc. It is important to make the distinction between writing that is for therapy and writing that employs literary techniques and skills that also has implications for wellbeing and positive transformation. Autoethnographic teaching and practice should, in my opinion, adhere to the latter. While self-narration can be cathartic, "the classroom is not a clinic.” (Cardell and Douglas, 2016). When working with students on their own auoethnographies, the emphasis is on transformational writing that employs skill and retains a sense of technique and craft. In this way, the process can empower students to develop as writers and as people and this can help them to see themselves more clearly as writing practitioners. This can be useful for how they envisage themselves and their discipline in the world outside the classroom once they graduate.

\section{Teaching Autoethnography}

"I expressed some long felt and deeply felt emotion. And in expressing it I explained it and then laid it to rest." (Woolf, 1989, p.90)

Despite my ambivalence about our current political climate and the implications it has for HE, my feelings regarding what a privilege it is to work with students have not changed since I first joined the University of Brighton in 2006. Working with students to develop their confidence with ideas and helping them to understand storytelling in a range of genres is a pleasure that continues to challenge and develop me in parallel with their own evolution as writers, thinkers, people. And perhaps this is at the core of what the writing and sharing of our stories is all about? It is an act that helps us to consciously or subconsciously think about our humanity and what it means to be human. And of course there is a compelling argument that to some extent all writing is autobiographical or at least draws on our lived and imagined experiences of the world. With this firmly in mind, one of the first things I tell my students is 'don't feel you have to share the most difficult thing that has happened to you'. It is my responsibility as a tutor to create a dynamic space for the students to work in but it must also feel safe and supportive. Students are asked to share their writing with their peers every week and we discuss strategies for making this a 
constructive and positive experience including guidelines on things to look out for in each other's writing and appropriate responses. We also talk about why it is important to help each other to develop confidence with writing whilst simultaneously offering constructive criticism that will ensure our writing improves, otherwise there is no trajectory for the students to go on, their work will flat line and their sense of what 'good' writing is will not broaden and enrich, making the entire module pointless or certainly less productive. Even after the warning that no one should feel overly exposed or unnecessarily vulnerable by writing about traumatic and painful autobiographical events, some students often choose to disclose and story things that have been difficult. The writer is advised to mine those events and journey to those places that are still troubling for us, because it can make for rich storytelling and also because there are therapeutic dimensions to this process that can be healing and transformative (Hunt, 2000). My thesis contains a script that details my own experiences with trauma following stress at work, health issues and the breakdown of a long term relationship. The process of researching and writing the script was of huge benefit to my own wellbeing and helped to me to feel differently about work, home and my writing. And so while asking them to venture into autobiographical writing about trauma is always with a cautionary precursor, it is also important that I use my own experiences and understanding about life writing in my teaching, in the hope that it will be empowering and positive for the students too.

Coffey (1999) criticises autoethnography for having narcisstic and naval gazing properties and naturally, any study of self runs the risk of being indulgent or overly self-interested. When I teach autobiographical writing to undergraduates, we discuss issues of why one should write their autobiography, the aesthetics of autobiographical narratives (Nalbantian, 1994) and editing their work so that the focus remains on writing well and not just exposing themselves on the page. They are also given examples of autobiographical texts to digest and discuss within their peer group. This process of reading, thinking and discussion enables students to connect their writing to the ethics of what they write and how and why they write it and this conscious layering between themselves and their writing develops knowledge, techniques and the confidence to apply these to their own writing, thus reducing any narcisstic tendencies and instead helping them to produce evocative and absorbing work. Whilst they must remain present in their autobiographical narratives, a process of attachment and detachment is important to all writers and can be developed and increased using autoethnography as it is a methodology that seeks to connect the individual to their social/cultural worlds. Instead of using autobiographical writing to just look in, autoethnographers have to look up and out as well. Autoethnographers engage in a 
cycle of reflection and action, often triggered by wanting to find something out about themselves in relation to the wider world and this critical process of self-analysis and understanding in relation to cultural and social discourses can help to make sense of their own lives by reconceiving their perspectives in relation to others.

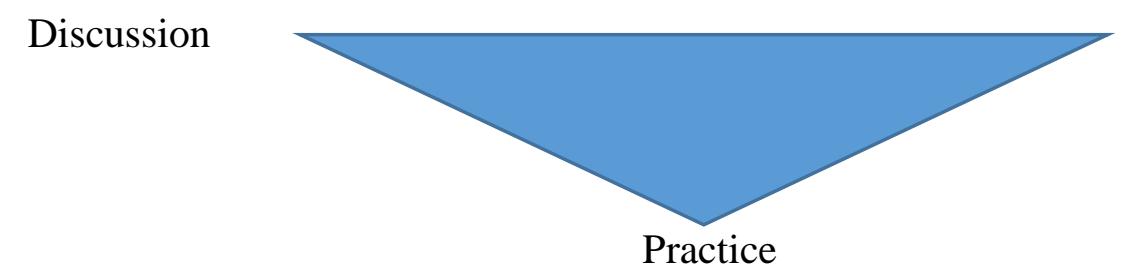

Reflection

Fig. 1 - Triangulation of Practice

Engaging students in a triangulation of discussion - reflection - practice can help them to 'make new sense of situations of uncertainty or uniqueness' that they might experience (Schon, 1983, p. 61) and these are crucial research skills that have the potential to help them make sense of their academic studies and lived experiences whilst at university. Not only can this help them to feel surer about their writing and their studies but it may also impact on their well-being (Moriarty and Reading, 2012).

Once students have been introduced to writing autobiographical narratives, I then offer examples of auoethnographies and we explore the notion of employing self-narratives to examine the situatedness of self in relation to others in a social construct (Reed-Danahay, 1997; Spry, 2001). We look at examples of autoethnography as a social process whereby individuals come to greater understanding of themselves and others (Schubert, 1986, p.33) as a result of their writing (Carless and Sparkes, 2007; Grant, 2010; Moriarty, 2015). I ask the students to consider how their own writing and research might illuminate readers and by engaging them in a vivid and evocative narrative that is: "ethnographical in its methodological orientation, cultural in its interpretive orientation, and autobiographical in its content orientation” (Chang, 2008, p. 1). But this can still make it difficult for students to develop connections between lived experiences, academic study and their social worlds. This lack of clarity can be damaging for their confidence with their research and so, inspired by the work of Carless and Sparkes (2007) and Sikes (2011), I have devised the following guiding questions that I recommend students practising autoethnography ask themselves and their readers/audiences:

- Does the story hold together in an intelligible and coherent manner? 
- Do the characters and events seem plausible?

- What might readers/audiences learn from the writing - about the social world under study and also about themselves?

- Did the writing affect the reader/audience emotionally and/or did it resonate personally?

- Can the reader empathise with any of the characters or not?

It is a series of questions I have used in my own work and it can help to refocus or motivate the work at stuck points in the research. While supporting the students to become independent researchers and thinkers, guiding questions such as these are useful. They provide a criteria that students can return to in their assessed work at university but also when they graduate and use their writing in post-graduate or professional work.

Guba and Lincoln (1989) advanced four authenticity criteria essential in autoethnographic study: fairness, ontological authenticity, educative authenticity, catalytic authenticity and tactical authenticity. The fourth criterion, catalytic authenticity, is "the extent to which action is stimulated and facilitated by the evaluation process," (Guba \& Lincoln, 1989, p. 249) where the purpose is some form of action or decision making. Lather (1981) argues that research that has catalytic authenticity should have "reality altering effect and channel impact so that participants gain self-understanding and, ultimately, self-determination through research participation” (p. 68). This sense of transformation as a result of self-study and of feeling differently about oneself as a result of the research process is particularly useful for students about to graduate from university and develop a sense of themselves and their discipline of study in the world outside the classroom. This is a potentially intense process that can benefit from one-to-one supervision away from the classroom and peer support that may increase feelings of vulnerability for any student engaging in an autoethnographic process. For these reasons, I have found it particularly useful to work with final year and post-graduate students on autoethnographic approaches as it can evoke a range of emotions and feelings that the student does not fully begin to make sense of until the work is underway or even complete. In this way, the writing becomes a method of enquiry, a notion that is supported by Richardson (2000) who suggests that: "Writing is also a way of knowing - a method of discovery and analysis. By writing in different ways, we discover new aspects of our topic and our relationship to it. Form and content are inseparable,” (p.923). 
In 2010, one of my third year students approached me and asked if he could do a creative dissertation. Luis (not his real name) had taken other creative writing modules and while his work had been sound, it was safe. He had worked as a fashion model and was popular with the other students, whilst maintaining an aloof separation that only increased his kudos. I had watched him take part in writing exercises without giving much away about what he thought or felt which I assumed was because the degree was just a stepping stone and an experiment in how much socialising you could do and still pass. He struck me as the sort of student who coasted but was bright enough to do well. I had judged him and deemed him to be taking the creative dissertation route because he thought it was the easy option. Slightly cynically, I tried to warn him off. And then he told me what he wanted to do. And he told me why. And I realised I had been utterly wrong about him. He explained that he had been holding onto difficult autobiographical experiences that he had buried deep within himself but were beginning to affect him in ways that were taking over his life. When we finished talking he said: "I don’t want to feel like this anymore. I want the happy ending.”

Of course I could not and did not promise him that, but I gave him some articles where the researchers had employed autoethnography and asked him to think about what his project might be like. We also talked about the ethical implications of storying traumatic experiences and how this might impact on him and what he might consider to help with this. It soon became clear that he had no interest in producing a conventional dissertation. I also gave him my own writing and explained why I had felt an urgency to story my experiences with working in HE and how the process had helped me to feel differently and more positive about my role as an academic but also as mother, daughter, friend, partner, colleague, sister, woman too. Luis decided that he wanted to use his critical and creative work to hold up a mirror to his life and experiences with mental health issues and reflect what it had been like for him. He was not seeking any kind of truth or definitive solution to how he had been feeling, he simply hoped that by merging his research and evocative writing, it would help to facilitate positive changes in his life and that it might trigger an enlightened (Kant, 1794) response in those who read his work. Denzin and Lincoln (2008) describe qualitative researchers who are interested in interpretive, narrative, theoretical, political, cultural techniques as 'bricoleurs' or quilt-makers as they seek to offer a patchwork montage of their research experiences, drawing on a range of skills, techniques and genres to project a version of the research that is evocative, messy and openly imperfect. Luis identified this model as being appropriate for his research as he argued mental health issues (much like any life experiences) are not experienced in a linear format or only in one way. By employing different genres, he wanted 
to create a split narrative drawing on poetry, memoir and script to tell a story that was messy, that was complicated, that was lived. It might not be deemed perfect by the people marking his dissertation but it was how it had to be done in order for it to maintain its importance and transformational potential for Luis himself and he hoped that anyone reading his work would respect and engage with this. We started to explore what the different sections of his patchwork would look like, the tools he would need to create them and how he might stitch them all together.

He worked incredibly hard. Absorbing articles and books and sending me his writing for critique and discussion. Tutorials were intense as different emotions and awareness's emerged as he worked. He simultaneously engaged with a counselling service, recognising that the writing process and aspects of the therapy might overlap at times but that they were also separate. Whilst we both accepted that there was an undeniable therapeutic dimension to the process, we were both clear that I am not a counsellor and that, in this context certainly, he was not a patient: our focus was on the writing. I worried if he was going to hold everything together or if the pressure of completing his final year together coupled with unlocking this Pandora's Box of how he had been feeling and living would be too much, but when we discussed the ethical implications on his own well-being, he was resolute: “I just can’t feel like this anymore.” And he kept going.

\section{$\underline{2 A M}$}

My mind wanders hopelessly.

I tend to think about

Something that happened

4 years ago, or something

That happened 1 hour ago,

My mind takes me to the future

And somewhere 10 years from now.

Bleak.

My mind is like a hurricane,

Wreckage. 
It's full of beautiful yet

Horrible things.

Loss of breath joins

My wandering mind,

The storm is sucking me in.

(Luis, 2010)

By the time Luis handed in his dissertation, the storm had passed. The present and the future stopped seeming like desolate and tortured places and he started to talk about his life after graduation with optimism and relief. The process of writing about trauma had helped him to see his experiences in a new way and he felt differently about them and also about himself. Instead of feeling happy for him, I panicked. What if it didn't get through the marking process? Or what if it did but achieved a mark that failed to reflect his blood, sweat and tears? What if I had encouraged him to write in a way that was deemed too personal and/or creative? Of course I did not reveal these fears to Luis. I just waited for the marker's report with a growing sense of dread that the system he had believed in might ultimately let him down.

When Luis graduated with a first and was also awarded a prize for his outstanding dissertation, it was a moment of joy and of hope. He has stayed in touch and I am honoured to hear about the English teacher he is becoming and how motivated he is to work with his pupils, to hear their stories and to try and help them to see the value in their own processes of writing and reflection. He has even written a chapter for a collection of narratives from teaching that I am co-editing where he talks about his writing and how it has helped him to encourage his own pupils to use their own work to develop their writing skills and selfconfidence. I often talk about how he came to write his dissertation and what it meant - to him but also to me. Watching students be brave, be vulnerable and their commitment to the process of developing their craft and evolving as writers, academics and as people, remains the biggest inspiration to my own teaching. Through our writing and sharing of stories, our interpersonal exchanges accord us subject positions, and these serve to guide the moral direction of our individual and social lives (Davies \& Harre, 1990; Harre, 1991). Writing in this way can help some students to evolve and recover from traumatic experiences, to feel better prepared for their professional and personal lives postgraduation and more confident about what is to come. And if and when the storm returns, they can feel surer about finding a way through. 


\section{Conclusion}

I have slowly come to believe that no story is true for all time and space: we invent our stories with a passion, they are momentarily true, we cling to them, they may become our lives and then we move on. (Plummer, 1995, p.170)

I have worked with students on their auoethnographies for several years now and the processes are always slightly different but on each occasion the practice of creation and crafting has been transformative, uplifting, life affirming. For the student, but also for me. I will always be grateful to each one of them for allowing me some insight into their individual practice and change. By using their research and writing to understand and make meaning about themselves and their social, cultural, political, emotional worlds, students can evolve past notions of themselves as just learners and begin to accept themselves as writers with something personal and academic to say about the humanities and about creative writing. I have found this of particular use with dissertation students and on a module with MA students where they become artists' in residence and have to work with a group/organisation on a co-devised creative brief that employs their research skills and creative writings. Students often pick residencies that have a personal relevance and resonance and working in this way can help them to navigate through their residencies and produce work that is personal and social.

But using autobiographical narratives in research is hard and students can and should be supported with this process. A criteria I suggest they are given for developing autoethnographic work is the following:

Students should:

1. Be clear about what they want to write and why;

2. Be able to identify literary techniques that they have employed to make their writing vivid;

3. Be actively engaged in a process of crafting and critique;

4. Be clear about how this connects to the social world

5. Be willing to engage in a transformative process. 
Working in this way can support students to make sense of the world and to let their sense of it become vivid through their craft of writing. In this way they can use their writing to reflect and shape their lives as they enter post-graduation. They can develop as better researchers, writers and thinkers and use this to help them fulfil their personal ambitions. I have found that working in this way can help them to develop their technique and craft, enhance their self of self, help them to recover from traumatic experiences, feel more confident about their place in their discipline of creative writing and the place that their discipline has in the world outside the lecture hall. They realise their writing matters. And it really does.

\section{Bibliography}

Canagarajah, A. S. (2002). Geopolitics of Academic Writing Pittsburgh: University of Pittsburgh Press

Cardell, K. \& Douglas, K. (2016) Why literature students should practise life writing. Arts and Humanities in Higher Education 1474022216635825, first published on March 8, 2016 doi:10.1177/1474022216635825

Carless, D., \& Sparkes, A. (2007). The physical activity experiences of men with serious mental illness: Three short stories. Psychology of Sport and Exercise, 9(2), 191-210.

Chang, H. (2008). Autoethnography as method. Walnut Creek, CA: Left Coast Press.

Charney, D. (2011) The Power of Making, V\&A.

Clough, P. (2002). Narratives and Fictions in Educational Research. Buckingham and Philadelphia: Open University Press.

Coffey, P. (1999). The ethnographic self. London, UK: Sage.

Davies, B. \& Harre, B. (1990). Positioning: The Discursive Production of Selves. Journal for the Theory of Social Behaviour, 20(1), 43-63.

Denzin, N. K., \& Lincoln, Y. S. (2008). Strategies of Qualitative Inquiry (3rd ed.). Thousand Oaks, CA: Sage.

Denzin, N. K. (1992). The many faces of emotionality. In C. Ellis (Ed.), Investigating subjectivity: Research on lived experience (pp. 17-30). London: Sage. 
Denzin, N. K. (1997). Interpretive ethnography: Ethnographic practices for the 21st century. London: Sage

Docherty, T. (2012). Research by Numbers. Index on Censorship, 41 (46), 46-54.

Ellis, C. (1995). Final negotiations: A story of love, loss, and chronic illness. Philadelphia:

Temple University Press.

Ellis, C. (2004). The ethnographic I: A methodological novel about teaching and doing autoethnography. Walnut Creek, CA: Mira.

Ellis, C., \& Bochner, A.P. (2000). Autoethnography, personal narrative, reflexivity: Researcher as a subject. In N. K. Denzin \& Y. S. Lincoln (Eds.), The handbook of qualitative research(pp. 733768). Thousand Oaks, CA: Sage

Ellis, C. \& Bochner, A. (Eds.). (1996). Composing ethnography: Alternative forms of qualitative writing. Lanham, MD: AltaMira Press.

Frank, A. W. (2011). What is dialogical research and why should we do it? Qualitative Health Research, 15, 964-974.

Gilles, V., Harden, A., Johnson, K., Reavey, Goodall, H. L. Jr. (1991). Living in a rock and roll mystery: Reading context, self and others as clues. Carbondale, IL: Southern Illinois University Press.

Guba, E., \& Lincoln, Y. (1989). Fourth generation evaluation. Beverly Hills, CA: Sage Grant, A. (2010a). Autoethnographic ethics and rewriting the fragmented self. Journal of Psychiatric and Mental Health Nursing, 17, 111-116.

Grant, A. (2010b). Writing the reflexive self: an autoethnography of alcoholism and the 'Impact' of psychotherapy culture. Journal of Psychiatric and Mental Health Nursing. 17(7), 577-582. Grant, A., \& Zeeman, L. (2010). Postmodern geography, mental health nursing and the contribution of short story form ethnography. University of Brighton. Hunt, C. (2000) Therapeutic Dimensions of Autobiography in Creative Writing. Jessica Kingsley Publishers: London, Philadelphia.

Harre, R. (1991). The Discursive Production of Selves. Theory \& Psychology, 1(1), 51-63.

Kant, I. (1794, 1996). An Answer to the Question: What is Enlightenment? In M. J. Gregor (Ed.), Practical Philosophy. Cambridge: Cambridge University Press.

Knights,B.(2008)"Teaching and writing as complementary processes",in Gregorzewska, M. and Korzeniowska, A.,(eds) Duet encounters, Warsaw: Wydawnictwo Uniwersytetu Warszawskiego, 2008 Lather, P. (1991). Getting smart: Feminist research and pedagogy with/in the postmodern. New York, NY: Routledge. 
Lucal, Betsy. 1999. What it means to be gendered me: Life on the boundaries of a dichotomous gender system. Gender and Society 13, no. 6: 781-97 Moriarty, J. (2015). Leaving the blood in: Experiences with an autoethnographic doctoral thesis. In N. Short, Zeeman, L., \& Grant, A. (Ed.), British Contemporary Autoethnography. Rotterdam, Boston, Taipei: Sense.

Moriarty, J. (2016) Autobiographical and researched experiences with academic writing: an analytical autoethnodrama, , 2(1), NAWE, 0-0

Moriarty, J. (2015a). Analytical Autoethnodrama. Rotterdam, Boston, Taipei: Sense.

Moriarty, J. (2015b). Leaving the blood in: Experiences with an autoethnographic doctoral thesis. In N. Short, Zeeman, L., \& Grant, A. (Ed.), British Contemporary Autoethnography. Rotterdam, Boston, Taipei: Sense.

Moriarty, J and Reading, C (2012) Linking creative processes with personal, vocational and academic development in cross-disciplinary workshops. International Journal for CrossDisplinary Subjects in Education (IJCDSE), Special Issue, Vol 1 Issue 2 ISSN: 20426364 (Online), http://www.infonomics-society.org/LICEJ/Published\%20papers.htm Nalbantian, S. (1994) Aesthetic Autobiography: From Life to Art in Marcel Proust, James Joyce, Virginia Woolf and Anais Nin. Basingstoke: Palgrave MacMillan.

Plummer, K. (1995). Telling sexual stories: Power, change and social worlds . London:

Routledge.

Reed-Danahay, D.E. (1997). Auto/ethnography: rewriting the self and others. New York, NY:

Berg

Richardson, L. (2000) 'Writing: A Method of Inquiry’ in Denzin, N. \& Lincoln, Y. (Eds) The Handbook of Qualitative Research $2^{\text {nd }}$ Edn Thousand Oaks, Sage, pp. 923 - 948.

Richardson, L. and E. St Pierre (2005). Writing: A method of inquiry. Handbook of Qualitative

Research. N. Denzin and Y. Lincoln. London Sage: 61-73.

Schon, D. (1983). The Reflective Practitioner. New York: Basic Books

Schubert, W.H. (1986). Curriculum: perspective, paradigm, and possibility. Ann Arbour, MI:

Macmillan Publishing Company.

Sikes, P. (2000) 'Truth and Lies Revisited’ British Educational Research Journal 26, 2, pp. 257 270.

Sparkes, A. C. (2002). Telling Tales in Sport and Physical Activity: A Qualitative Journey. Leeds: Human Kinetics.

Spry, T., (2001). Performing autoethnography: An embodied methodological praxis. 
Qualitative Inquiry, 7(6), 706732. Retrieved from http://www.nyu.edu/classes/bkg/methods/spry.pdf

Woolf, V. (1989) 'Sketch of the past' In Moments of Being. London: Grafton Books. pp.72-173 